\title{
PRODUÇÃO AUDIOVISUAL COMO INSTRUMENTO DE EDUCAÇÃO AMBIENTAL: EXPERIÊNCIA EM UNIDADE DE CONSERVAÇÃO
}

\author{
Ivy Panagassi ${ }^{1}$ \\ Monique Fernanda Setin² \\ Nathalie Aprígio Assis ${ }^{3}$ \\ André Aparecido Malavazzi ${ }^{4}$
}

Resumo: A produção audiovisual, ao estimular os sentidos e significar os lugares, contribui para o aprendizado no contexto da Educação Ambiental. Desse modo, busca-se relatar a experiência de produção de um documentário sobre uma Unidade de Conservação, tendo como embasamento a relação entre audiovisual e Educação Ambiental. O objetivo do documentário é sensibilizar a coletividade sobre as questões ambientais e históricas da área. Elaborou-se o planejamento do documentário, após deu-se a elaboração do roteiro geral e cronograma, seguido das filmagens, edição e exibições. Durante a experiência da produção e exibição constatou-se a importância da utilização de produção audiovisual para atrair visitantes e sensibilizar a população do entorno.

Palavras-chave: Educação Ambiental, Unidade de Conservação, Audiovisual.

Universidade Estadual Paulista UNESP. E-mail: ivy.panagassi@gmail.com

2 Universidade Estadual Paulista UNESP. E-mail: monique setin@yahoo.com.br

3 Universidade Estadual Paulista UNESP. E-mail: nathassis@gmail.com

${ }^{4}$ Universidade Estadual Paulista UNESP. E-mail: amalavazzi@yahoo.com.br

Revbea, São Paulo, V. 12, No 5: 126-139, 2017. 


\section{Introdução}

A produção audiovisual é carregada de significados históricos, culturais e afetivos. Mesmo que o objetivo principal da produção não seja de relatar acontecimentos históricos ou culturais está implícito esses elementos na mesma. Oliveira Jr. (2005, p 29) contribui ao destacar as geografias presente nos filmes:

Há nas imagens e sons fílmicos, permanências históricas, culturais, arquetípicas....ainda que não sabia o produtor delas. Ali estão como vibrações de uma "memória coletiva" dispersa em nossos corpos. Pode ser que reverberem em nós, pode ser que não.... Se sim, comporão nossa geografia do filme, se não, talvez venham a compor a geografia que outro nos der a ver no filme e aí então tornar-se-ão ali existentes também para nós $[\ldots]$.

Nesta perspectiva, para Azevedo (apud CORRÊA, ROSENDAHL, 2009: p.78) tanto filmes como documentários "são representações a respeito da realidade geográfica". Desse modo, podem reproduzir as "memórias coletivas" a respeito do espaço, território, paisagem e lugar. A interpretação do audiovisual está sujeita a polivocalidade, isto é, o espectador atribui significados de acordo com sua imaginação e experiência, cada espectador cria, então, o lugar fílmico.

Temos, então, o audiovisual como ferramenta com potencial para criação de vínculos entre espectador e o espaço que é representado, colocando dessa forma a dimensão geográfica como um dos elementos intrínsecos do cinema, junto com a dimensão histórica, cultural e arquetípicas. Conforme Corrêa e Rosendahl (2009, p.7.) deve-se considerar o audiovisual através da ótica da espacialidade:

Cinema e música são duas linguagens nas quais são expressas visões de mundo e sentimentos diversos, a despeito das diferenças entre ambas. Como criações sociais, podem ser vistas sob a ótica da espacialidade, atributo intrínseco a toda ação humana.

Magalhães (2007) também contribui ao colocar que a inter-relação com audiovisual de cunho educativo desperta os sentidos e resgata memórias e, junto com eles, a curiosidade inconsciente de ampliar a instrumentação sensorial e expandir o universo de conhecimento. Ou seja, ao estimular vários sentidos do espectador (como audição, visão e percepção sensorial), a linguagem audiovisual mostra-se no contexto educativo sensibilizadora, potencializadora e criadora de novos sentidos no âmbito do universo de cada um, contribuindo assim para o aprendizado. 
Essa relação simbiótica entre a produção audiovisual e o aprendizado também se dá no contexto da Educação Ambiental (EA), temática esta que se apresenta de modo transversal no conteúdo das disciplinas formais ou no contexto dos espaços educativos não formais, como é o caso das Unidades de Conservação (UCs).

Desenvolver atividades de EA está de acordo com os objetivos conservacionistas das UCs, ao passo que possibilita estreitar os vínculos e a afetividade entre a unidade, os moradores do entorno e os visitantes, estimulando, dessa forma, a participação na proteção daquela área.

Nesse sentido, como uma das atividades executadas durante estágio no Departamento de Manejo Florestal da Prefeitura Municipal de Rio Claro, localizado no interior da UC "Floresta Estadual Edmundo Navarro de Andrade" (FEENA), foi realizada a produção de um documentário intitulado "Horto: contos e encontros", partindo da perspectiva de utilizar o material audiovisual como uma ferramenta de Educação Ambiental em UCs, sensibilizando e potencializando novos sentidos para a existência e importância desses territórios protegidos.

Um dos objetivos do documentário é de sensibilizar a coletividade sobre as questões ambientais e históricas da unidade. Baseado nisso pretendeu-se difundir uma perspectiva histórica da FEENA, a partir da visão de pessoas que possuem ligação afetiva com o lugar, dando importância à memória de cada indivíduo na construção das representações coletivas dos cidadãos de Rio Claro sobre a FEENA. Bem como mostrar a importância de preservação da área nos aspectos históricos, culturais e ambientais para a cidade e a região.

A partir das relações e elementos entre obras fílmicas e Educação Ambiental será descrito neste artigo o processo de produção do documentário e sua exibição tanto na unidade quanto sugestões para exibição no contexto escolar com vistas a contribuir com a conservação da FEENA, utilizando, dessa forma, o audiovisual como uma ferramenta de Educação Ambiental.

\section{Material e Métodos}

\section{Localização da área de estudo}

A produção do documentário "Horto: contos e encontros" ocorreu nas dependências da Floresta Estadual Edmundo Navarro de Andrade, localizada na cidade de Rio Claro, interior de São Paulo. A UC tem como coordenadas geográficas Latitude $22^{\circ} 25^{\prime} \mathrm{S}$ e Longitude $47^{\circ} 33^{\prime} \mathrm{W}$. Com área de 2.230,53 hectares, encontra-se na bacia hidrográfica do rio Corumbataí (Figura 1). 
Floresta Estadual Edmundo Navarro de Andrade - FEENA

Instituto Florestal

Secretaria do Meio Ambiente

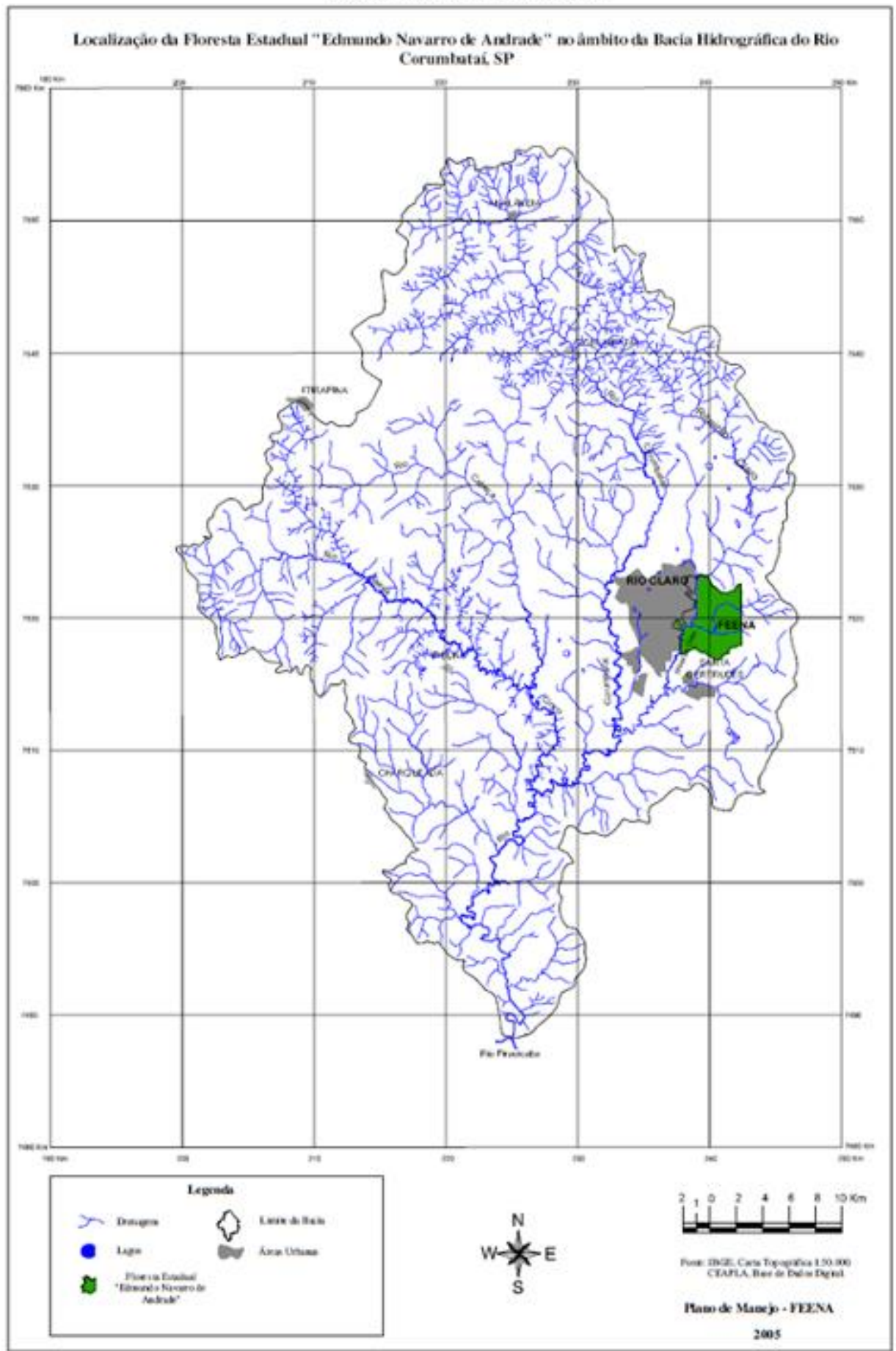

Figura 1: Mapa de localização da FEENA na bacia do rio Corumbataí Fonte: São Paulo (2005).

Revbea, São Paulo, V. 12, № 5: 126-139, 2017.

revista brasileira de
educação
ambiental 


\section{Histórico da FEENA}

No início do século XIX, Antônio Paes de Barros, futuro Primeiro Barão de Piracicaba, casa-se com Euphrosina de Aguiar adquirindo assim terras para cultivo de café que se tornaram as fazendas Santo Antônio e São João. Terras, estas, que se tornaram mais tarde a FEENA.

A história das terras da UC tem ligação com a criação da cidade de Rio Claro. O primeiro Barão de Piracicaba, antigo dono de terras que hoje são da FEENA, conseguiu com sua influência política e econômica a elevar o povoado de Morro Azul, hoje Rio Claro, para a categoria de cidade (ALVES; PERINOTTO, 2012).

Em 1909 a Companhia Paulista de Estrada de Ferro adquiriu as terras que pertenciam a Paes de Barros com intuito de reflorestar a área (uma vez que grandes áreas de florestas nativas já haviam sido devastadas) para produzir matéria-prima, a qual serviu para construção e manutenção da linha férrea com objetivo de escoar a produção de café para o Porto de Santos. Conforme aponta Daher et al. (2009, p.4):

A ferrovia não havia sido afetada até 1890. Porém, com o aumento excessivo do custo do carvão mineral, a solução imediata estava na utilização de lenha, cuja produção ainda era farta. Bastaram 30 anos, porém, para que as matas às margens da ferrovia fossem inteiramente dizimadas.

No ano de 1916, a Companhia Paulista comprou duas fazendas, Santo Antônio e Cachoeirinha, para ampliar as terras já mencionadas para reflorestamento, totalizando 720 alqueires. Foi neste contexto que em 1903, Edmundo Navarro de Andrade, recém-formado em Engenharia Agronômica pela Escola Nacional de Agricultura de Coimbra, foi contratado pela Companhia Paulista de Estrada de Ferro para realizar pesquisas em busca da melhor espécie de árvore para fornecer matéria-prima para a ferrovia. Depois de cinco anos de estudo chega à conclusão que espécies do gênero Eucalipto, originário da Austrália, eram as que tinham um rápido crescimento, boa qualidade para a finalidade requerida e adaptável às condições ambientais do estado de São Paulo.

Navarro, que antes residia e trabalhava no Horto de Jundiaí, muda-se para o Horto de Rio Claro, local que se tornou a sede do Serviço Florestal da Companhia Paulista. Em Rio Claro continuou desenvolvendo suas pesquisas voltadas para entomologia, fauna, técnicas de implantação de viveiro e plantio envolvendo estudos de adaptação e crescimento de 144 espécies exóticas do gênero Eucalyptus. Navarro morre em 1941 deixando um imenso legado para a Silvicultura.

No decorrer da década de 1970 a Companhia Paulista tornou-se estatal, 
passa, portanto, a ser administrado pela FEPASA.

Houve no ano de 1974 o início do processo de tombamento do Horto de Rio Claro pelo Conselho de Defesa do Patrimônio Histórico, Artístico, Arqueológico e Turístico (Condephaat) no Estado de São Paulo. Saindo em 1977 a decisão favorável pelo tombamento.

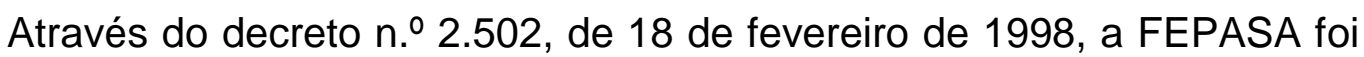
incorporada pela Rede Ferroviária Federal S.A. - RFFSA, porém, o Horto Florestal "Edmundo Navarro de Andrade", não fez parte do leilão, e tornou-se responsabilidade da Secretaria de Meio Ambiente do Estado de São Paulo, através do Instituto Florestal.

Pelo decreto 46.819 de 11 de junho de 2002, o Horto Florestal foi alterado para "Unidade de Conservação de Uso Sustentável", inserido na categoria de Floresta Estadual, passando a ser chamado de Floresta Estadual Edmundo Navarro de Andrade. Atualmente a gestão é feita pela Fundação Florestal.

\section{Metodologias}

A primeira fase consistiu no planejamento do documentário. Nesta etapa foi realizada uma pesquisa sobre a história da FEENA, tanto por meio de levantamento bibliográfico, quanto pela história oral de pessoas que visitam, trabalham ou moram no entorno da unidade. Pessoas estas que as idealizadoras do documentário conheceram durante suas vivências de estágio dentro da UC. Algumas dessas pessoas chamaram mais atenção por conta do seu envolvimento afetivo pela área. Dentre as pessoas que se teve contato, seis delas se dispuseram a participar do documentário, compartilhando suas experiências e afetividades.

Para estruturar o documentário, foram feitas diversas pesquisas bibliográficas na área ambiental sobre UC's, Educação Ambiental, diversidade ambiental, ecoturismo, parques estaduais paulistas, visitação pública em UC, políticas públicas, preservação e conservação do meio ambiente, ações de cidadania, sustentabilidade, patrimônio histórico entre outros temas a fim de criar familiaridade com a área de interesse a ser exibida em vídeo.

O levantamento fotográfico foi realizado no Arquivo Histórico da Prefeitura Municipal de Rio Claro, o qual cedeu fotografias antigas da área da atual FEENA para serem utilizadas no documentário.

Após as primeiras pesquisas começou a elaboração do roteiro geral, no qual foram discutidos entre as idealizadoras quais assuntos seriam importantes para ser inserido e de que forma se daria esta inclusão e em qual ordem de aparição.

Elaborou-se, também, nesta fase um cronograma estipulando data para as entrevistas e posterior edição.

Muitas das imagens que foram capturadas para o documentário

revista brasileira educação ambiental 
ocorreram de modo espontâneo, sendo consideradas como instantes de imagens que se mostraram perante a câmera. Por exemplo, os instantes que foram capturados durante a filmagem como a cena dos cachorros correndo, das borboletas e pássaros voando, até mesmo os sons do lugar, o balançar das árvores. Era como se aquela imagem, aparecesse no instante "correto".

Já outras imagens foram buscadas de acordo com as necessidades que se mostrava perante as narrativas dos entrevistados. Por exemplo, quando filmamos o Museu, o Centro de Convivência e etc. Foram imagens feitas com intuito de relacionar a fala do entrevistado com as formas geográficas.

As entrevistas contaram com perguntas abertas, devido a necessidade de respostas mais livres e subjetivas. Foi aconselhado e explicado no início de cada entrevista que se tinha por objetivo destacar alguns assuntos gerais, tais como, as histórias sobre a FEENA, a ligação dos entrevistados com a Unidade, a importância, tanto em termos ambientais, como histórico-culturais para a região onde ela se insere. Entretanto, por se tratar de recuperação da história viva, as perguntas elaboradas tinham papel apenas de iniciar e orientar as entrevistas de tal forma que as pessoas ficassem à vontade para expressar suas respostas abertamente. Isto é, tentou-se direcionar o assunto da entrevista através de algumas questões, mas o entrevistado ficava livre para trazer os assuntos que os interessavam também.

Buscou-se realizar as entrevistas no contexto da FEENA, sendo que apenas uma entrevista foi realizada em um lugar fora da UC, atendendo às necessidades particulares de um dos entrevistados. Lugares com paisagens cênicas foram escolhidos como pano de fundo para a filmagem dos entrevistados, conforme Figura 2. Os equipamentos utilizados para as filmagens e fotografia foram: câmera fotográfica e filmadora Nikon D500 e filmadora Sony ActionCam HDR-AS15.

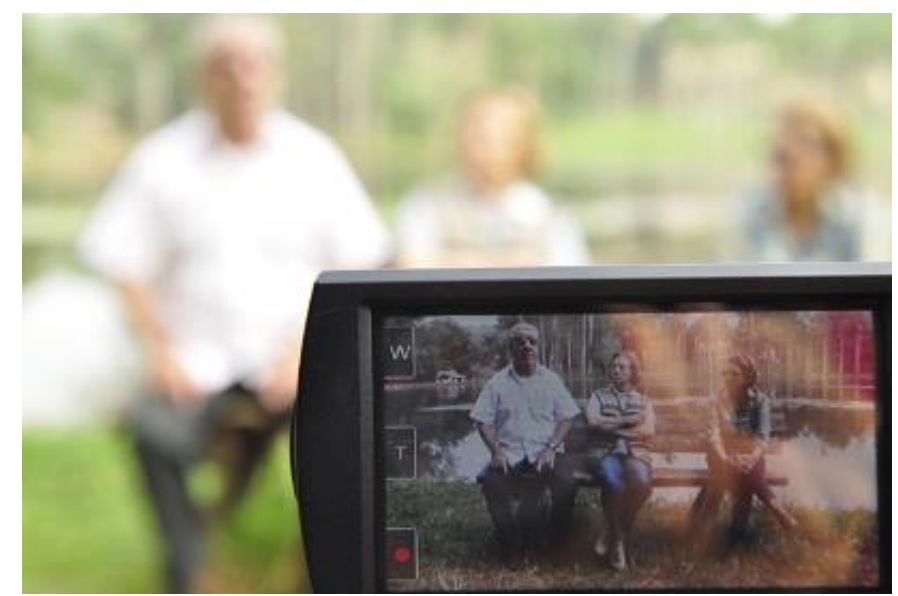

Figura 2: Local e câmera de uma entrevista Fonte: Autoria própria

Após finalizar as filmagens de todas as entrevistas, ensaios fotográficos 
realizada a edição do documentário no Adobe Premiere Pro CS6. A ordem de aparição dos entrevistados foi definida somente no processo de edição, conforme a seguinte sequência:

- $\quad 1^{\text {a }}$ Entrevistado: Sr. Osmar Antônio de Campos Ribeiro (ex-diretor da Associação Amigos do Horto)

- $\quad 2$ Entrevistado: José Marcos Dias (ex-funcionário da FEPASA)

- $\quad 3^{a}$ Entrevistado: Dona Fátima Aparecida Jorge (ex-diretora da Associação Amigos do Horto)

- $\quad 4^{a}$ Entrevistado: Oswaldo Vieira das Neves (aposentado que há 23 anos frequenta a FEENA)

- 5 a Entrevistado: Entrevista: José Luiz Timoni (ex-diretor do Departamento de Manejo da Prefeitura de Rio Claro)

- $\quad 6$ Entrevistado: Sr. Augusto Parente Sobrinho (morador antigo da cidade de Rio Claro com vários parentes que trabalhavam na FEPASA e profundo conhecedor de histórias da região)

As imagens que foram exibidas durante a transição de cada entrevista foram selecionadas, também, durante o processo de edição. Depois de filmar vários lugares em diversos horários, foram capturadas muitas imagens de fauna e flora local. Somando-se a estas imagens, foram filmados alguns locais que são marcos para a história do lugar, possuindo uma importância histórica.

Com a versão final do documentário pronto, fizemos a primeira exibição no Auditório da Biblioteca da Unesp (Figura 3), na qual os entrevistados puderam ver pela primeira vez a versão final do documentário. A exibição foi aberta ao público, fez-se propaganda na UNESP, na FEENA e via internet convidando as pessoas para a estreia. Várias pessoas compareceram e logo após a exibição houve um bate-papo sobre a produção e o conteúdo do documentário. Cada um dos entrevistados recebeu uma cópia do documentário.

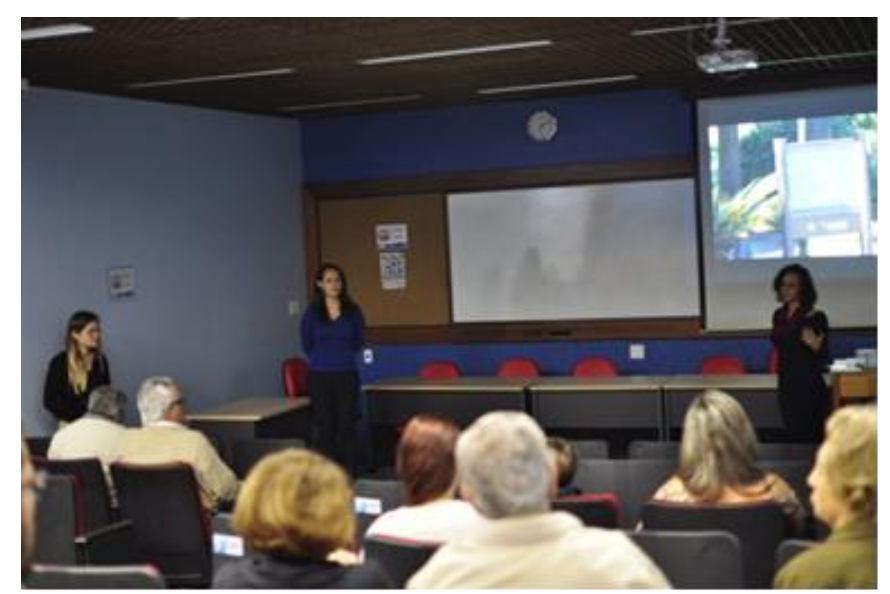

Figura 3: Primeira exibição do documentário

Fonte: Autoria própria 
A segunda exibição foi realizada durante a Semana do Meio Ambiente de Rio Claro de 2015 dentro da FEENA pela Prefeitura Municipal de Rio Claro, contando com a presença do Prefeito da cidade, funcionários da Prefeitura e da gestão da FEENA e frequentadores da unidade.

Disponibilizamos, também, uma cópia para a Associação Amigos do Horto para exibir em palestras e eventos organizados por esta associação sobre a unidade. Bem como, também disponibilizado no Youtube $<$ https://www.youtube.com/watch?v=p91iFhchGbc > para que interessados pela FENNA possam ter contato com a produção. O Youtube se mostrou um aliado como meio de divulgação, por ser um site gratuito, de fácil acesso e com grande alcance público, principalmente para as escolas.

\section{Resultados e Discussões}

\section{Experiência do processo de produção}

O documentário foi estruturado em forma de seis contos, isto é, narrativas breves de seis pessoas que partilharam suas histórias e memórias relacionadas à FEENA. Ao longo desse processo ocorreram vários encontros com visitantes e trabalhadores da FEENA, algumas dessas pessoas que conversamos se tornaram os entrevistados do documentário.

Como as idealizadoras do documentário eram além de moradoras do entorno da unidade, também estagiárias no Departamento de Manejo Florestal da Prefeitura de Rio Claro dentro da FEENA, o processo de conhecer pessoas importantes para a história da UC, pesquisar sobre a unidade e escolher os entrevistados, se deu no decorrer do estágio e da vivência como moradoras do entorno.

Cada pessoa contou durante a entrevista qual é seu envolvimento com a floresta, alguns compartilharam o entrelaçamento de sua história de vida com a história do lugar, ou relataram momentos da própria história da FEENA. Partes da história da unidade foram, contudo, contadas, a partir do ponto de vista e da vivência de cada indivíduo. Essa abordagem foi realizada não com o intuito de trazer a história oficial, foi, entretanto, uma abordagem voltada a resgatar a história da floresta segundo os olhos de cada um. Também comentaram no desenrolar da entrevista sobre a importância da floresta, tanto em aspectos históricos/culturais quanto em aspectos ambientais, para a cidade e região, bem como a necessidade de preservação da área.

Como havia um roteiro aberto de perguntas os entrevistados ficaram mais livres para compartilhar de suas experiências e histórias. No começo de cada entrevista explicamos para os entrevistados sobre o objetivo do documentário. Como já havíamos conversado sobre essas histórias anteriormente com cada um, estimulamos eles para contar algumas histórias que julgamos coerente com nossos objetivos, mas isso não impediu que surgissem novas histórias durante cada entrevista.

$O$ intuito de deixar os entrevistados mais soltos para dizer o que queriam Revbea, São Paulo, V. 12, № 5: 126-139, 2017. 
foi uma escolha coerente com nosso objetivo de mostrar a história do antigo Horto pelo viés de cada entrevistado, mostrando, assim, que não há somente a história oficial a ser contada, mas cada visitante ou trabalhador constrói sua própria relação e história com o lugar e estas histórias individuais também ajudaram a construir a história do lugar.

A escolha em entrevistar Sr. Osmar (figura 4) ocorreu pelo reconhecido conhecimento que este possui sobre a história da UC. Ao entrevistá-lo extraímos de sua fala aspectos importantes da história, bem como das formas geográficas da UC. Neste sentido, Seu Osmar nos explicou acerca dos porquês de cada "construção", tais como Casa central, Museu, Centro de convivência, além de nos revelar memórias afetivas dele com o local.

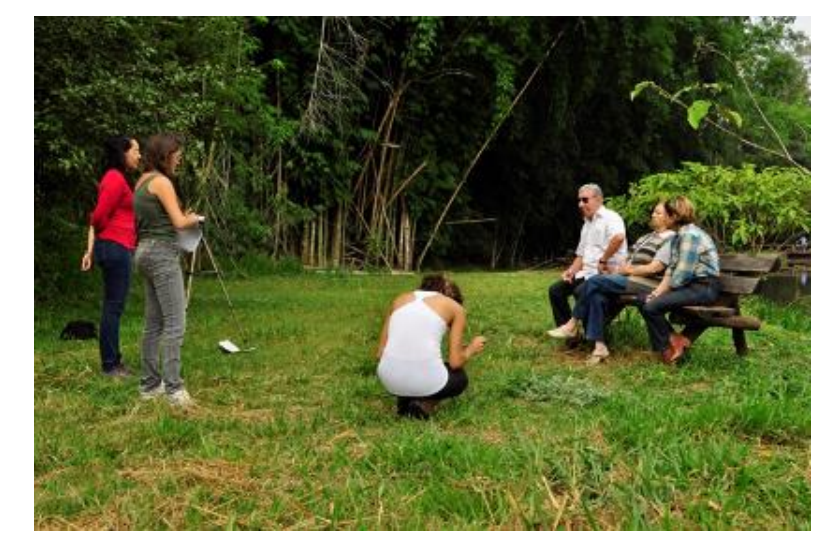

Figura 4: Entrevista com Sr. Osmar e Dona Fátima

Fonte: Autoria própria (2015)

Entrevistamos Marcos, o qual trabalhava na manutenção dos prédios da UC. Durante esta entrevista atentamos para extrair a vivência de Marcos enquanto trabalhador da FEENA, consequentemente, exprimimos a história de vida dele que se confunde com o lugar. Adentrar na floresta causa encantamento pela diversidade de espécies da fauna e flora, bem como sua monumental dimensão física, além disso há um misticismo gerado em torno de algumas histórias populares que acabaram por se tornar lendas, Marcos exprime isso em sua entrevista no momento em que relata sobre "escutar pegadas" pela escadaria do Solar e sobre um amigo ter visto o falecido Edmundo Navarro sentado em um dos bancos da floresta, experiências, estas, que compõe a magia do lugar.

Realizamos a próxima entrevista com Timoni, além de contribuir com as histórias dos personagens do lugar, sua principal colaboração ao documentário tratou-se em aprofundar a relevância da UC para com município de Rio Claro. Em sua fala, apresentou-se temas como: importância dos rios para o abastecimento de água da cidade; diversidade de fauna e flora; UC como corredor ecológico e refúgio dos animais; exercer influência sobre o clima da cidade e purificando o ar.

Seu Oswaldo (Figura 5) e seu Augustinho foram os últimos a serem entrevistados. O primeiro nos relatou o papel que a UC exerce no que tange ao 
lazer da região, uma vez que este faz caminhada há muitos anos no local. Seu Augustinho expôs a história de sua família, pois muito de seus familiares trabalhavam no local, ademais apresentou uma poesia de sua autoria, que foi colocada para finalizar o documentário.

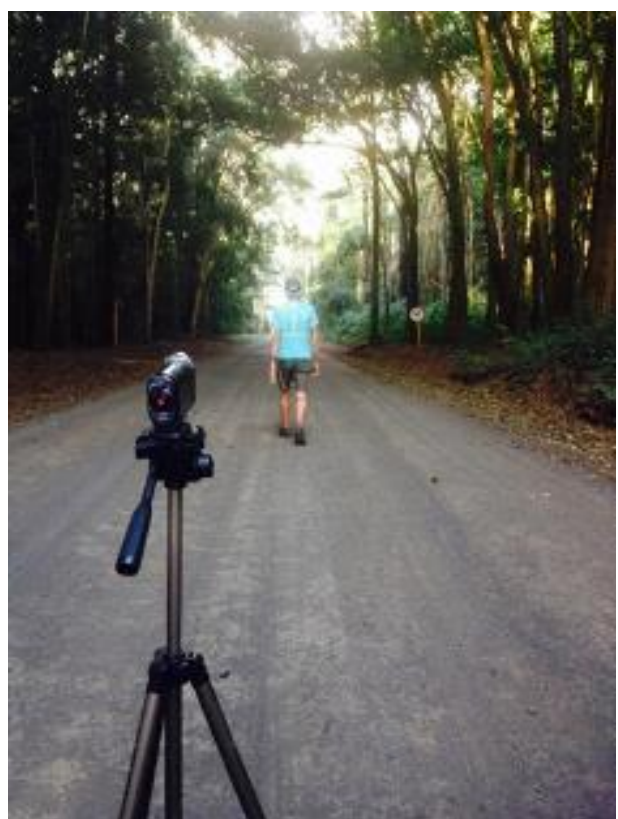

Figura 5: Final da entrevista com Seu Oswaldo Fonte: Autoria própria (2015)

Além das entrevistas que tínhamos previsto, ocorreu também a entrevista com a Dona Fátima que chegou como acompanhante do Seu Osmar. Apesar de não ser uma entrevista programada, sua contribuição ao documentário foi de extrema relevância, pois sua narrativa foi percorrendo caminhos que nos levaram ao âmbito da luta pela permanência do lugar, o engajamento social para a preservação do meio ambiente e da história local. Ela nos trouxe inquietações para mostrar, chamar a atenção e informar a sociedade, não somente para a beleza do lugar, mas também para o abandono da UC. Fatos, estes, importantes para compreender a interação que ocorre do homem com o meio, espaço e tempo.

Os entrevistados agradeceram ter esta oportunidade de poder falar livremente o que queriam sobre o "Horto" (denominação que a maioria dos frequentadores ainda dão a FEENA). Alguns como Sr. Osmar e Dona Fátima apontaram que foi positivo poder falar o que realmente queriam, sem serem direcionados ou perguntados sobre outro assunto de interesse do entrevistador.

O Marcos, também, ficou grato à oportunidade de participar do documentário, deixando ali registradas suas memórias afetivas com o lugar, que poderão dar novos olhares para quem assiste sobre sua visão do Horto. Ele nos disse que até hoje somente nós nos preocupamos em entrevistar os funcionários que não fazem parte da direção do local e vivem o cotidiano da Revbea, São Paulo, V. 12, № 5: 126-139, 2017. 
unidade.

Por fim, o processo de elaboração do documentário foi fruto de uma troca entre as possibilidades da UC, ou seja, o que o cotidiano do lugar proporciona, seus sons e imagens que por sorte a câmera capturava, além das imagens planejadas devido à necessidade que aparecia nos relatos. Quanto às entrevistas, também houve um processo de troca, entre o roteiro elaborado, bem como a contribuição da própria pessoa através de narrativas importantes que não havíamos posto no roteiro. O intuito do documentário foi que os espectadores vissem e que tivessem uma nova percepção de um lugar que sobrevive ao tempo e as transformações do espaço ao seu entorno.

\section{Experiência da exibição}

A exibição realizada na UNESP aconteceu no auditório da biblioteca da Universidade e foi pensada e planejada pelas idealizadoras do documentário. O objetivo da exibição na no ambiente acadêmico teve como impulso contribuir com o tripé da universidade que são o ensino, a pesquisa e a extensão. $A$ exibição do documentário se encaixa no processo de extensão, isto é, a exibição veio para estender à comunidade o conhecimento produzido através do instrumento audiovisual. Aproximando, desta forma, a universidade da comunidade, bem como com os órgãos ligados à prefeitura, já que estiveram presentes indivíduos ligados a universidade, a Prefeitura e a comunidade com um objetivo comum, de saber mais sobre a história da FEENA.

Além do objetivo ligado a extensão, outra finalidade era de exibir para os participantes (entrevistados, colaboradores e idealizadoras) do documentário o resultado final da produção audiovisual. Ao começar a assistir, aqueles que fizeram parte como entrevistado puderam se ver, reconhecer-se, ver suas imagens envoltos às fotografias e aos sons da trilha sonora, produzindo, assim, emoções e sentimento de pertencimento nesses indivíduos. Mesmo aqueles que não participaram do processo de elaboração do documentário, de outro modo também se reconheceram no trabalho, pois a floresta está presente no cotidiano dos indivíduos que vivem na cidade de Rio Claro, seja como lazer nos fins de semana, seja como parte do caminho percorrido diariamente. Portanto, ao transportar as imagens vividas para o audiovisual, conseguiu-se resgatar dos/nos espectadores sentimentos de reconhecimento e pertencimento quanto ao lugar FEENA.

Ao final da primeira exibição do documentário as idealizadoras comentaram sobre a produção, os objetivos e as expectativas em relação ao documentário e após, foi aberto um espaço para o debate, havendo grande participação dos presentes nas discussões sobre a importância das UCs, em especial da FEENA. Foi levantada, pelos próprios espectadores, a reflexão de que a unidade se encontra ameaçada pelo avanço da urbanização e de interesses imobiliários na área de proteção. Aproveitando a oportunidade do debate muitos dos entrevistados, alguns cujo histórico pessoal e profissional se confunde com a própria história da FEENA, puderam aprofundar as reflexões

revista brasileira educação ambiental 
postas e ampliar a discussão acerca das UCs.

A segunda exibição do documentário ocorreu na semana do meio ambiente da cidade de Rio Claro, o vídeo foi posto como a última programação do evento, ou seja, como forma de encerramento. Foi muito bem recebido por todos, até mesmo com aplausos. Autoridades da Prefeitura, além de funcionários da Fundação Florestal elogiaram o trabalho.

\section{Considerações finais}

A experiência de planejar e produzir um documentário na temática ambiental e histórica mostrou-se enriquecedora, ao contribuir para a nova geografia criada nos envolvidos e nos espectadores a respeito da espacialidade e importância histórica da FEENA para a região.

O fato do processo ter sido feito de modo participativo, contando com ideias, sugestões e informações vindas de várias conversas informais com pessoas que trabalham, moram ou frequentam com mais frequência o lugar, contribuiu para envolver todos os participantes com o lugar, e suscitar ideias de conservação da área.

A escolha por entrevistas com perguntas abertas, mostrou-se uma metodologia com resultados positivos para a elaboração do documentário, pois os entrevistados sentiam-se abertos para contar histórias que resgatavam na hora e também para dizer o que realmente pensam sobre o lugar. Ao deixar o momento da entrevista o mais leve e confortável possível para o entrevistado, eles sentiam-se livres para dar sua verdadeira opinião sobre o lugar, dois dos entrevistados relataram ao final da entrevista que eles já haviam dado outras entrevistas, mas somente com a gente foi possível dizer tudo o que realmente queriam.

Por meio das duas exibições que acompanhamos foi possível observar que as pessoas se envolveram com o documentário, pois, logo após, muitas perguntas e debates foram suscitados. $O$ fato das exibições terem sido feitas na cidade que sedeia a FEENA fez com que o interesse pela história local e o envolvimento com a causa ambiental aparecesse com mais facilidade.

Quando o documentário é produzido e exibido em um contexto local, as pessoas sentem-se envolvidas por meio de suas histórias pessoais com as temáticas abordadas, o que causa momentos de sensibilização em prol da conservação do patrimônio natural e históricos, despertando, assim, interesse na participação na gestão da unidade.

\section{Agradecimentos}

À Prefeitura Municipal de Rio Claro, a Universidade Estadual Paulista 'Júlio de Mesquita Filho' e a Floresta Estadual 'Edmundo Navarro de Andrade' que tornaram possível a elaboração do documentário. 


\section{Referências}

ALVES, U.D.; PERINOTTO, C. C. O importante personagem histórico que fundou a Fazenda Santo Antônio e protagonizou o desenvolvimento da cidade de Rio Claro. Revista do Arquivo. Rio Claro, p. 75-78.junho de 2012.

BRASIL. Decreto № 2.502, DE 18 de fevereiro de 1998. Disponível em: <http://www.planalto.gov.br/ccivil 03/decreto/D2502.htm> Acesso em: jul. 2016

BRASIL. Decreto № , 46.819, de 11 de junho de 2002. Disponível em: http://www.icmbio.gov.br/cepsul/images/stories/legislacao/Decretos/2002/dec s p 468192002 uc florestaestadualedmundonavarroandrade sp.pdf

Acesso em: jul. 2016

CORREAA, R.L.; ROSENDAHL, Z. Cinema, música e espaço. Rio de Janeiro: Ed. UERJ, 2009.

DAHER, C.S. et al. Conhecendo a Floresta: 100 anos de existência. Rio Claro, 2009.

MAGALHÃES, C.M. Os programas infantis da TV: Teoria e prática para entender a televisão feita para as crianças. Belo Horizonte: Autêntica, 2007

SÃO PAULO. Instituto Florestal. Plano de Manejo da Floresta Estadual Edmundo Navarro de Andrade. São Paulo, 2005.

OLIVEIRA JR., W.M. Leituras Transdisciplinares de Telas e Textos, Belo Horizonte, v.1, n.2, p.27-33, 2005.0 que seriam as geografias de cinema? Disponível em: <http://periodicos.letras.ufmg.br/index.php/txt/article/viewFile/8276/8338>. Acesso em: ago. 2016. 